\title{
Correction to: LncRNA PVT1 up-regulation is a poor prognosticator and serves as a therapeutic target in esophageal adenocarcinoma
}

Yan Xu ${ }^{1,2}$, Yuan $\mathrm{Li}^{1,2}$, Jiankang Jin ${ }^{1}$, Guangchun Han ${ }^{3}$, Chengcao Sun ${ }^{4}$, Melissa Pool Pizzi ${ }^{1}$, Longfei Huo ${ }^{1}$, Ailing Scott ${ }^{1}$, Ying Wang ${ }^{1}$, Lang Ma', Jeffrey H. Lee ${ }^{5}$, Manoop S. Bhutani ${ }^{5}$, Brian Weston ${ }^{5}$, Christopher Vellano ${ }^{6}$, Liuqing Yang ${ }^{4}$, Chunru Lin ${ }^{4}$, Youngsoo Kim${ }^{7}$, A. Robert MacLeod ${ }^{7}$, Linghua Wang ${ }^{3}$, Zhenning Wang ${ }^{2 *}$, Shumei Song ${ }^{1 *}$ and Jaffer A. Ajani ${ }^{1 *}$

\section{Correction to: Mol Cancer (2019) 18:141}

https://doi.org/10.1186/s12943-019-1064-5

Following publication of the original article [1], the authors identified minor errors in image-typesetting in Fig. 3; specifically the left hand side of Fig. 3d.

The corrected figure is given below. The correction does not have any effect on the results or conclusions of the paper.

\section{Author details}

'Departments of Gastrointestinal Medical Oncology, The University of Texas MD Anderson Cancer Center, 1515 Holcombe Blvd, Houston, TX 77030, USA. ${ }^{2}$ Department of Surgical Oncology and General Surgery, First Hospital of China Medical University, Shenyang 110001, People's Republic of China. ${ }^{3}$ Departments of Genomic Medicine, The University of Texas MD Anderson Cancer Center, Houston, TX 77030, USA. ${ }^{4}$ Departments of Molecular \& Cellular Oncology, The University of Texas MD Anderson Cancer Center, Houston, TX 77030, USA. ${ }^{5}$ Departments of Gastroenterology\&Hepatology, The University of Texas MD Anderson Cancer Center, Houston, TX 77030, USA. ${ }^{6}$ Center for Co-Clinical Trial, The University of Texas MD Anderson Cancer Center, Houston, TX 77030, USA. ${ }^{7}$ Ionis Pharmaceuticals, Inc., 2855 Gazelle Court, Carlsbad, CA 92010, USA.
Published online: 25 March 2021

\section{Reference}

1. $X U$ Y , Li Y, Jin J, et al. LncRNA PVT1 up-regulation is a poor prognosticator and serves as a therapeutic target in esophageal adenocarcinoma. Mol Cancer. 2019;18:141 https://doi.org/10.1186/s12943-019-1064-5.

The original article can be found online at https://doi.org/10.1186/s12943019-1064-5.

*Correspondence: josieon826@sina.cn; ssong@mdanderson.org; jajani@mdanderson.org

${ }^{2}$ Department of Surgical Oncology and General Surgery, First Hospital of China Medical University, Shenyang 110001, People's Republic of China ${ }^{1}$ Departments of Gastrointestinal Medical Oncology, The University of Texas MD Anderson Cancer Center, 1515 Holcombe Blvd, Houston, TX 77030, USA Full list of author information is available at the end of the article

(c) The Author(s). 2021 Open Access This article is licensed under a Creative Commons Attribution 4.0 International License, which permits use, sharing, adaptation, distribution and reproduction in any medium or format, as long as you give appropriate credit to the original author(s) and the source, provide a link to the Creative Commons licence, and indicate if changes were made. The images or other third party material in this article are included in the article's Creative Commons licence, unless indicated otherwise in a credit line to the material. If material is not included in the article's Creative Commons licence and your intended use is not permitted by statutory regulation or exceeds the permitted use, you will need to obtain permission directly from the copyright holder. To view a copy of this licence, visit http://creativecommons.org/licenses/by/4.0/ The Creative Commons Public Domain Dedication waiver (http://creativecommons.org/publicdomain/zero/1.0/) applies to the data made available in this article, unless otherwise stated in a credit line to the data. 


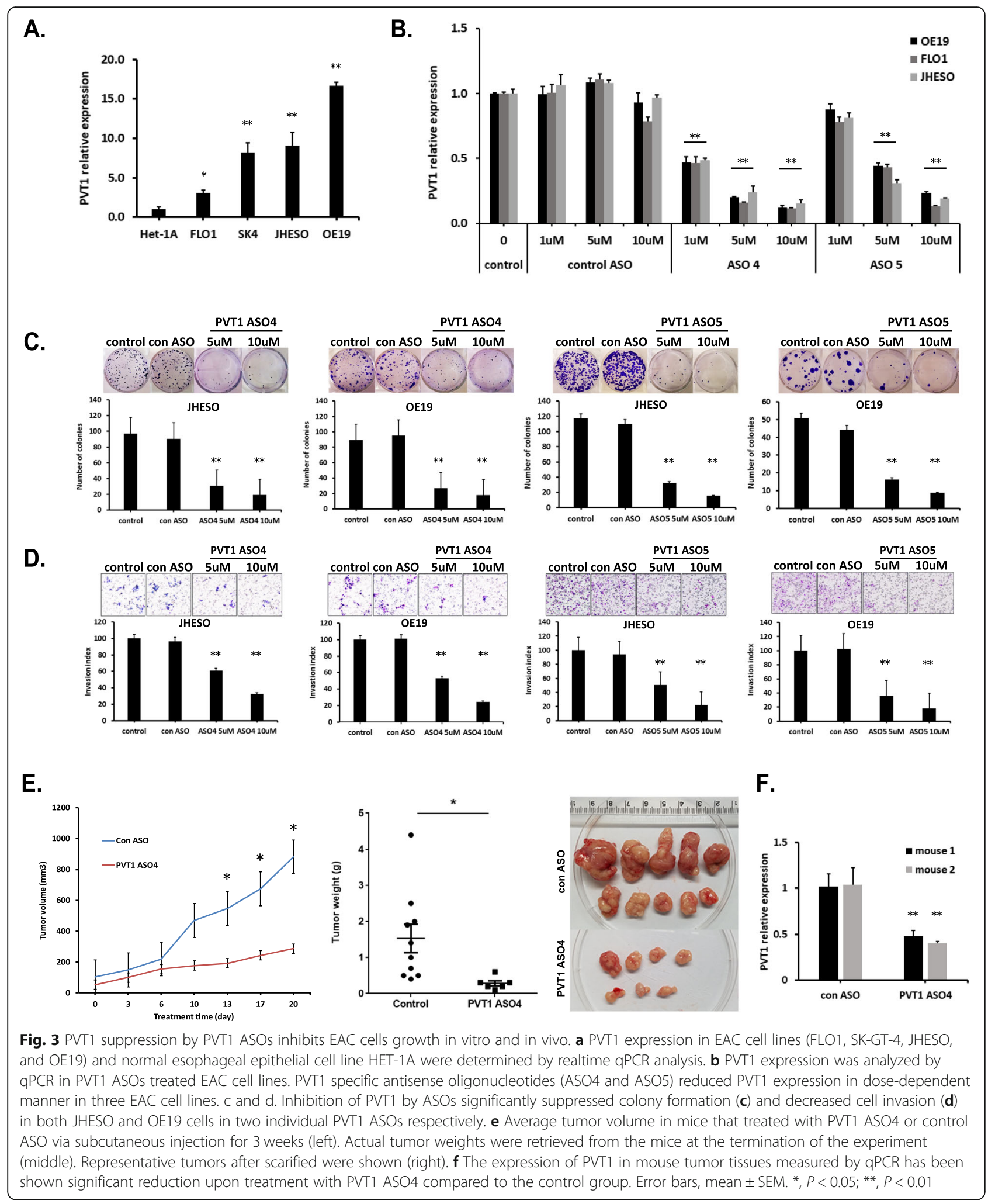

